

\section{The Scientific, Social and Ethical Aspects of Prolonging Human Life}
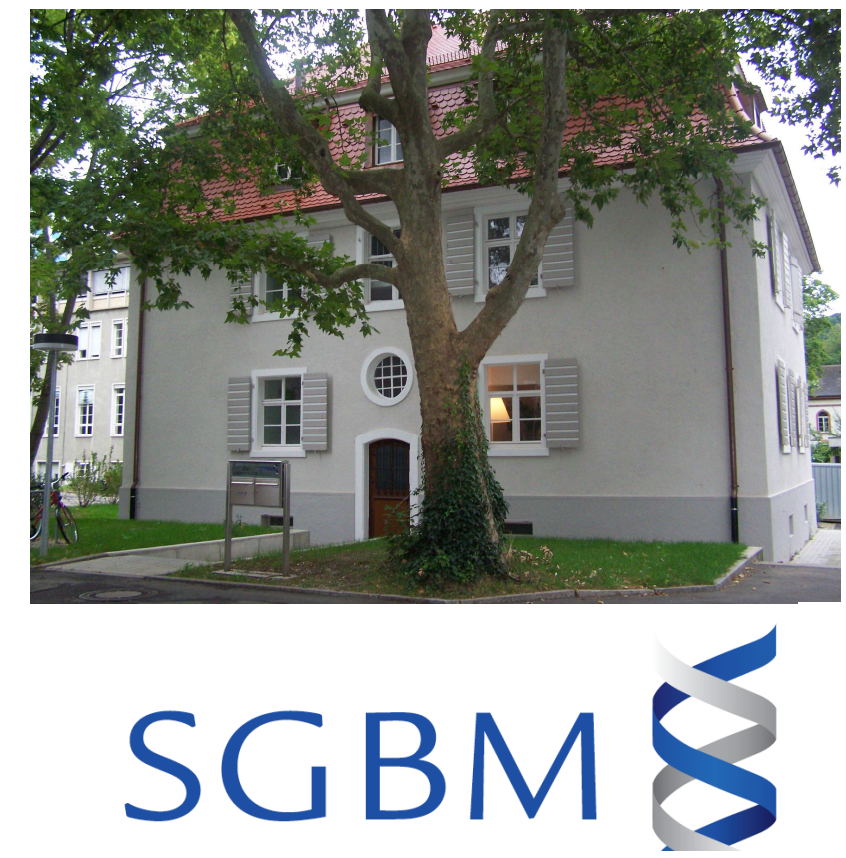

Spemann Graudate School of Biology and Medicine
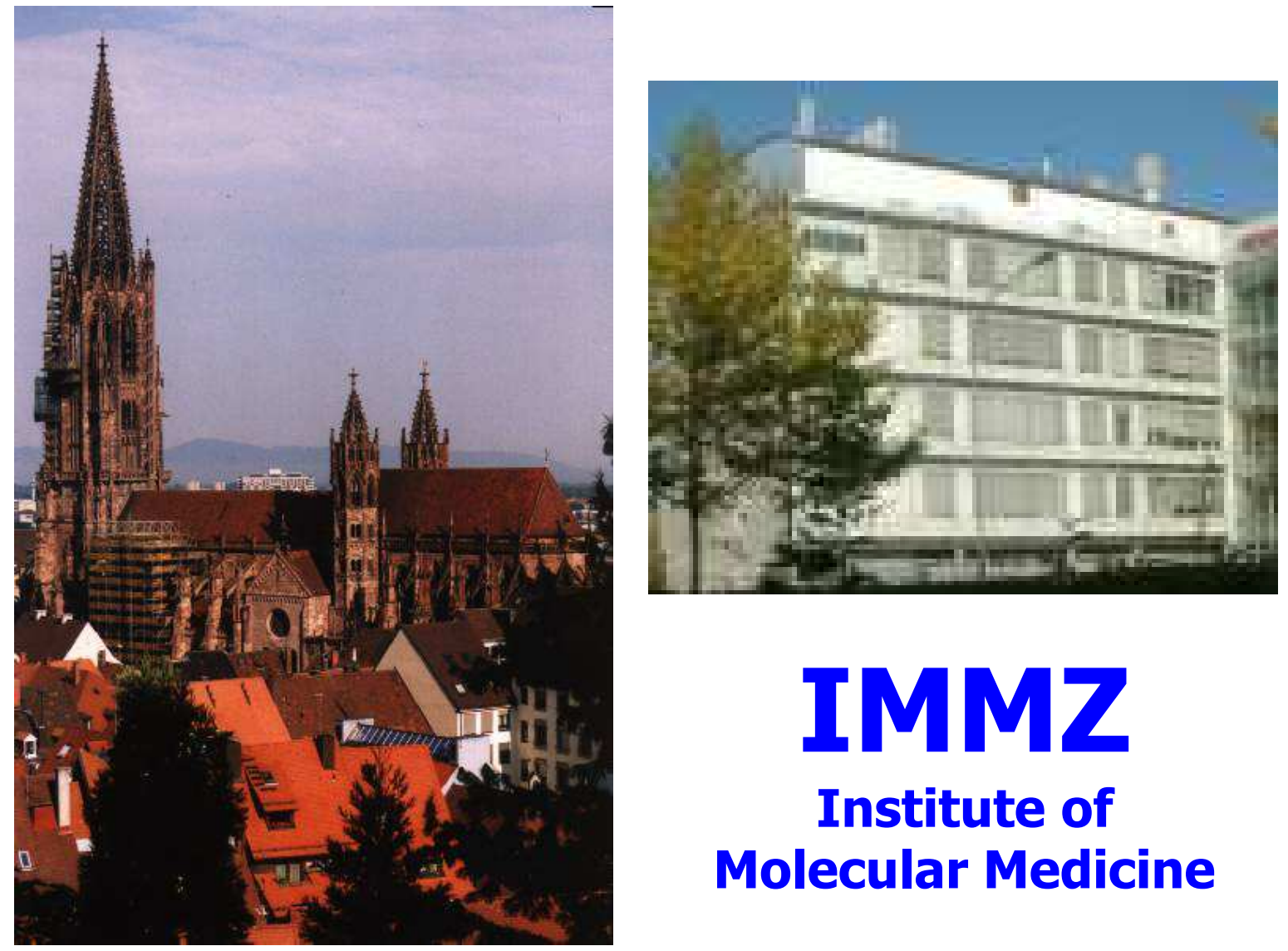

\section{IMMZ}

Institute of Molecular Medicine

Prof. Dr. Christoph Borner Albert-Ludwigs-Universität, Freiburg im Breisgau, Germany Symposium Science, Ethics and Society, Freiburg, 14.8.2015 
No (Cell) Life without (Cell) Death 


\section{Formation of fingers and toes (digits) during embryonic, fetal development is programmed \\ Cells die specifically between fingers and toes \\ (interdigital cells) at a particular time}
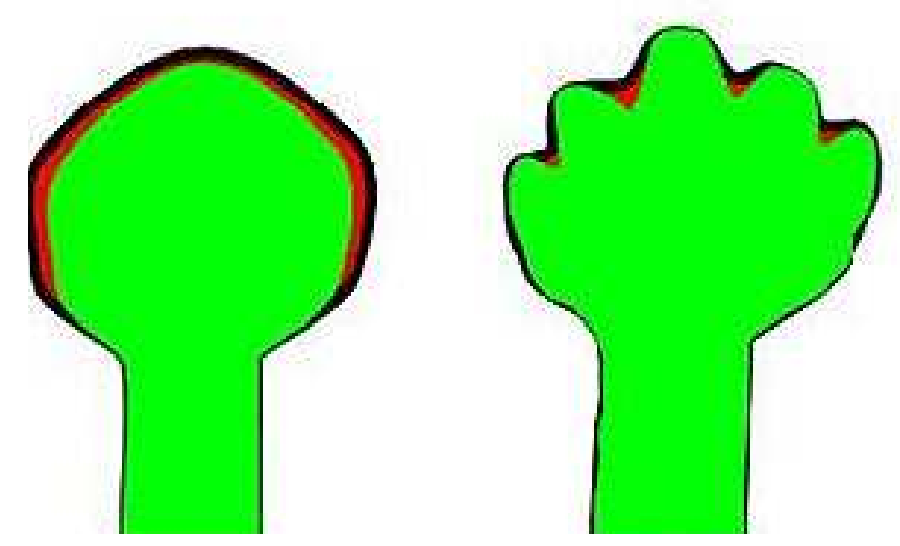

$\square \quad$ Living cells

Dying cells

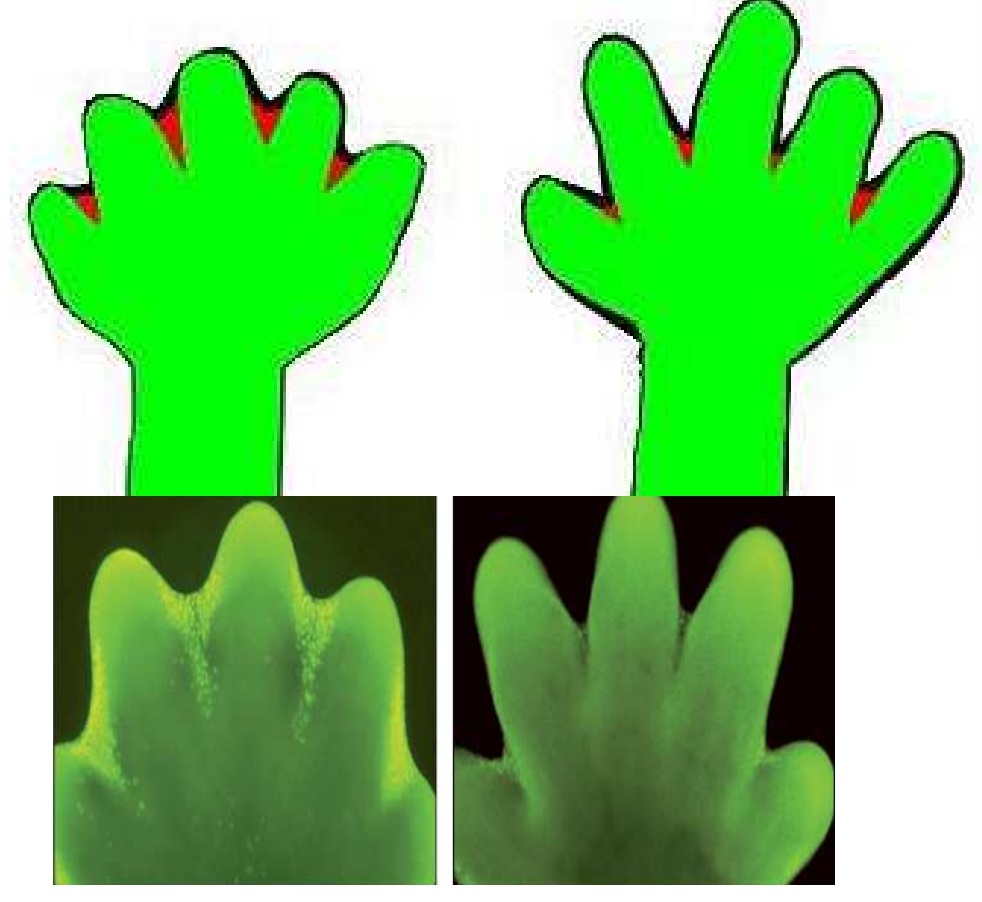

Source: Alberts et al. 2013 


\section{Interdigital cell death occurs exactly between day 52 and 59 in a human embryo}

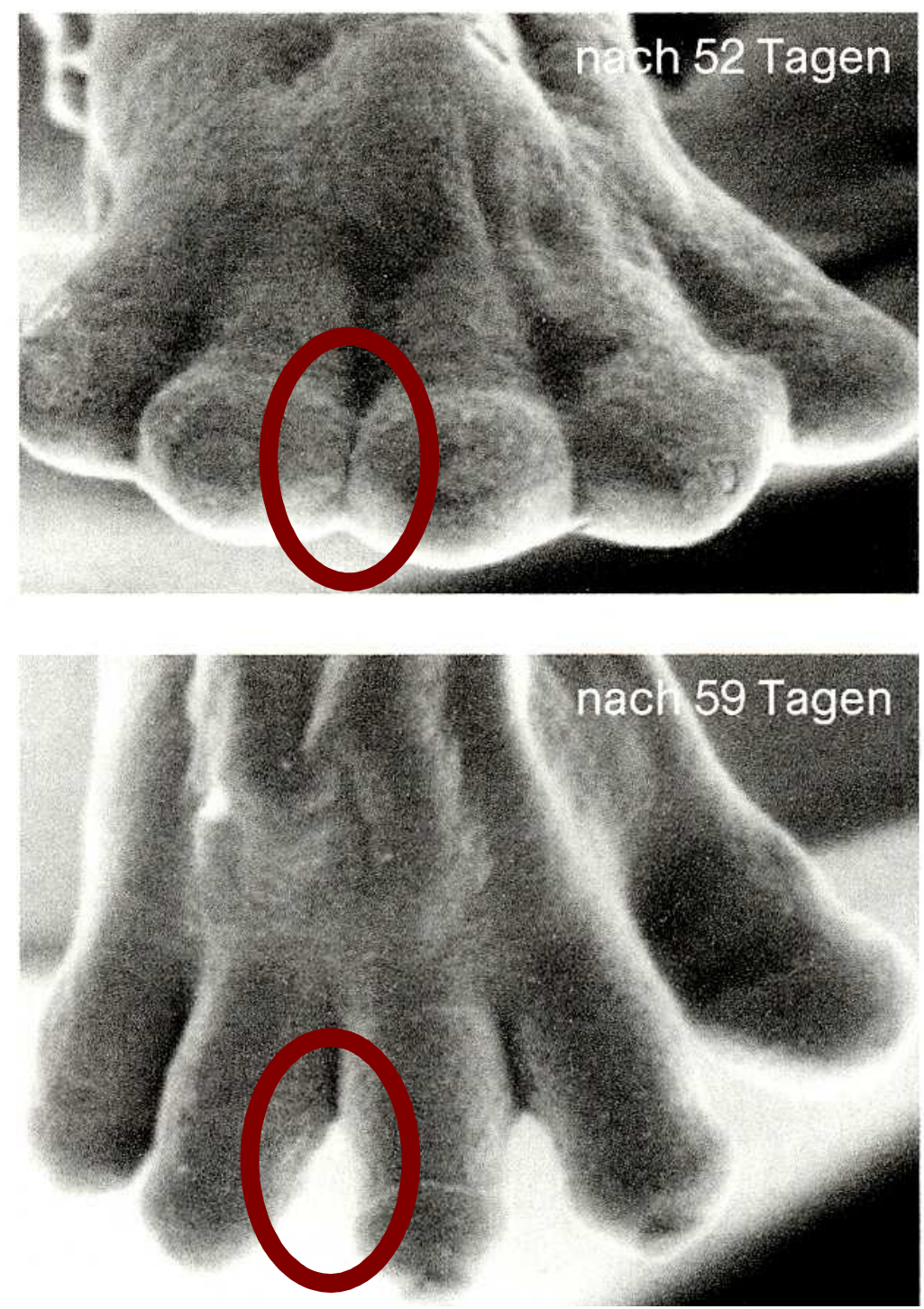

Interdigital cell death is not needed for ducks

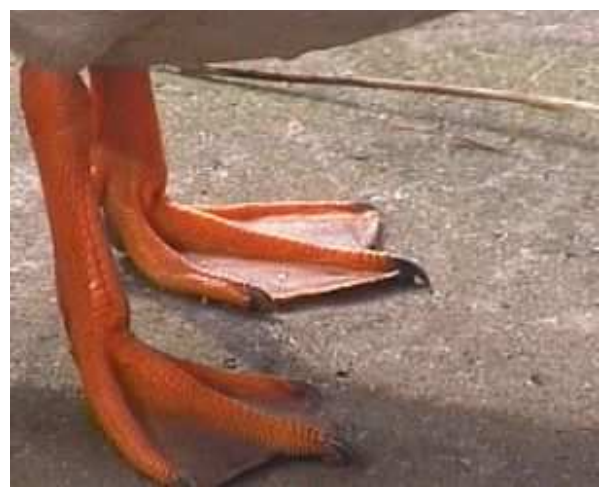




\section{Programmed cell death ensures the formation of hollow, tubular structures Blood vessels, peritoneum, digestive tract, glands, etc.}

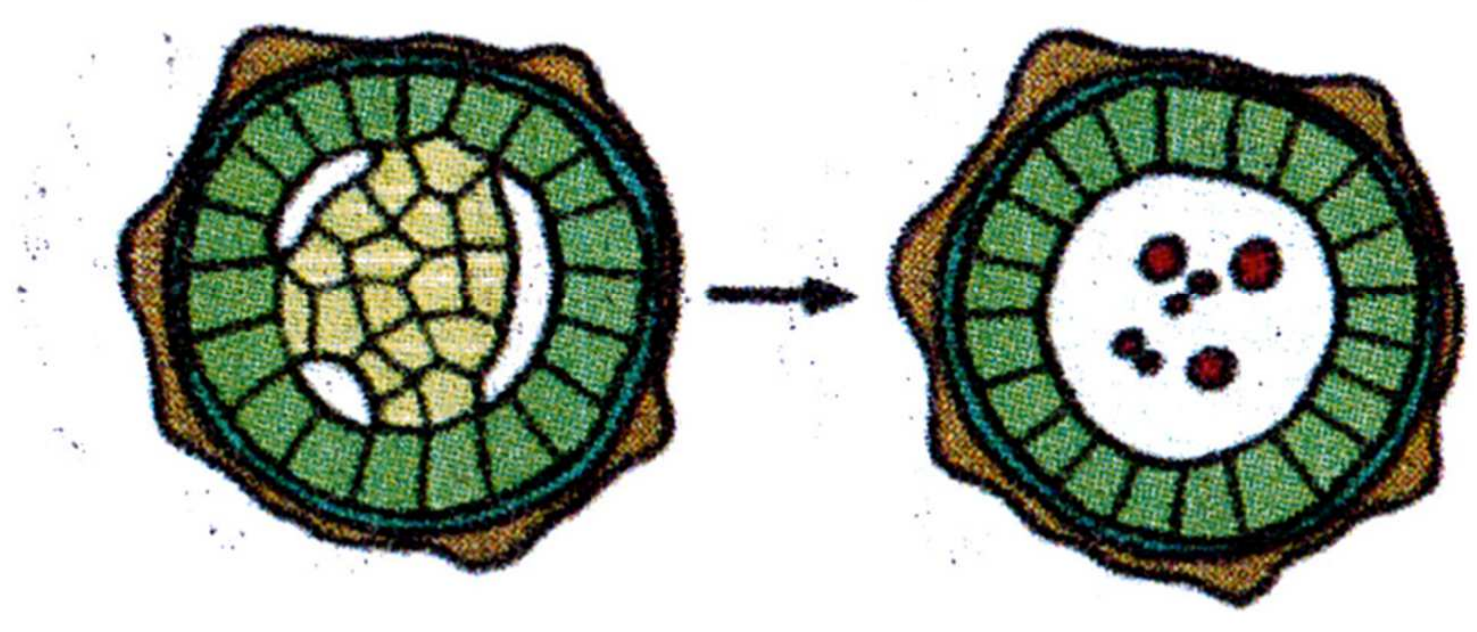




\section{Programmed cell death is crucial for the formation of reproductive organs}

Initially both systems are formed, but during the development one of them degenerates due hormonal regulation

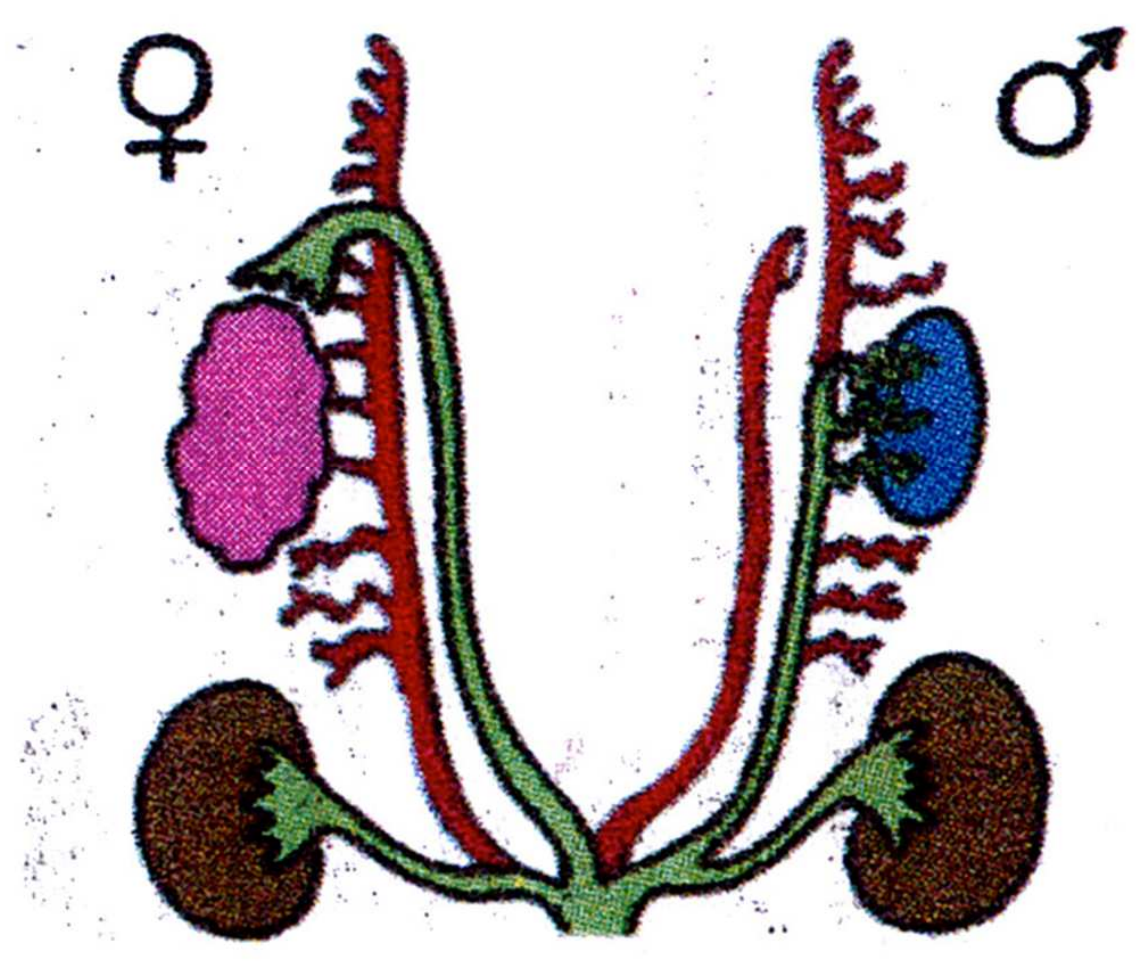




\section{Only those cells ("ducks") survive, which get enough nutrients/survival factors. The rest has nothing to eat and dies}

20 ducks

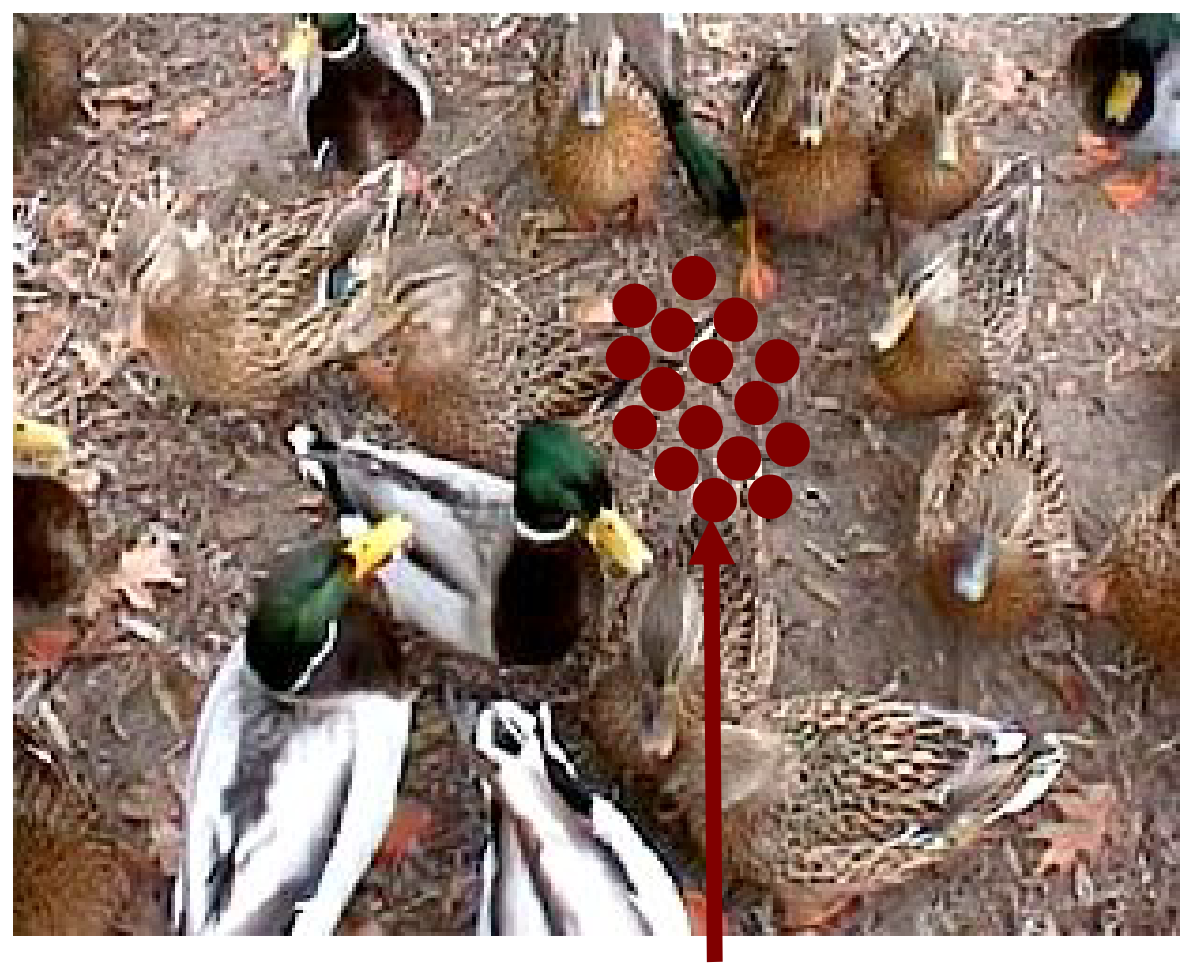

Limited amount of bread pieces
Only 8 ducks left

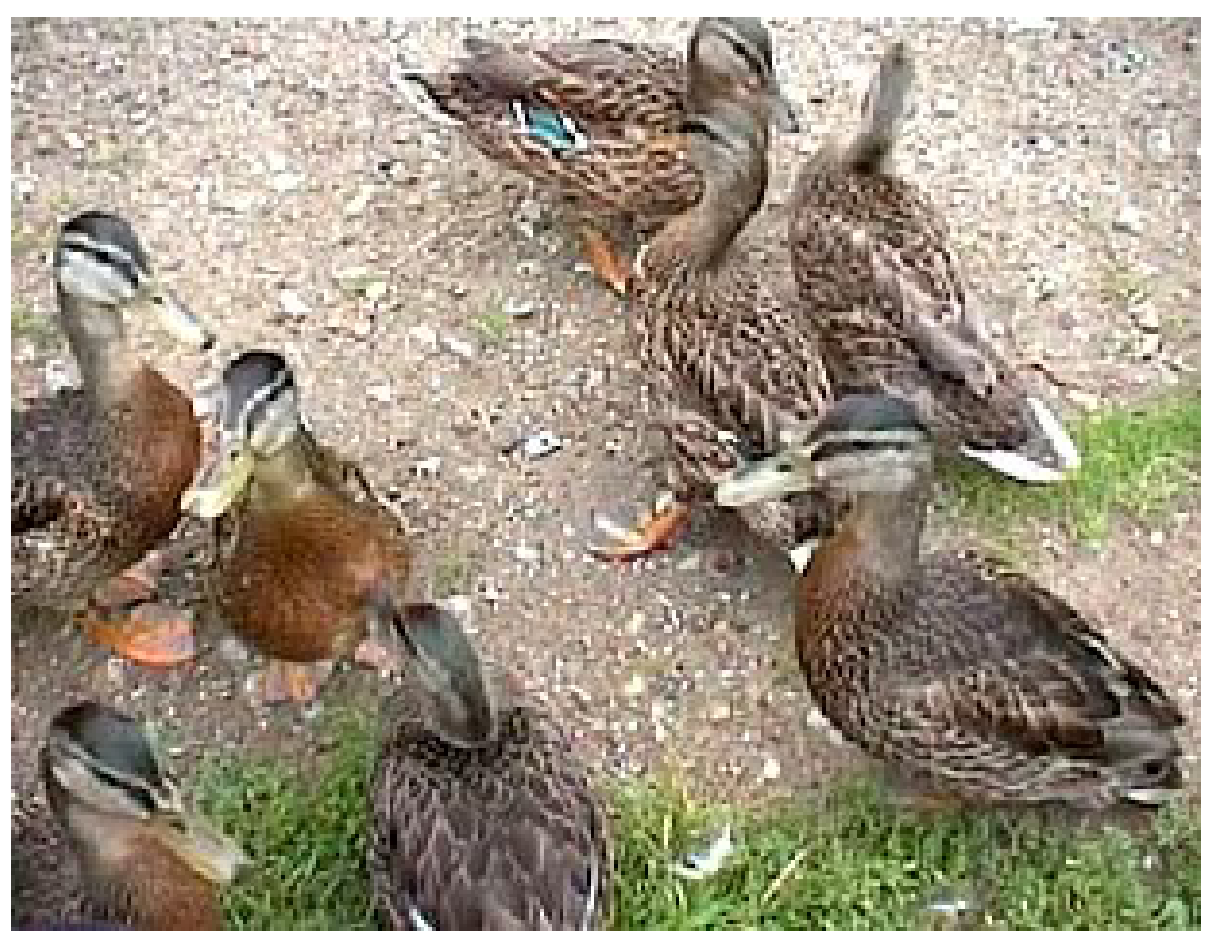

Survivors interact with each other and build a social network 


\section{Programmed cell death is essential to form the neuronal network}

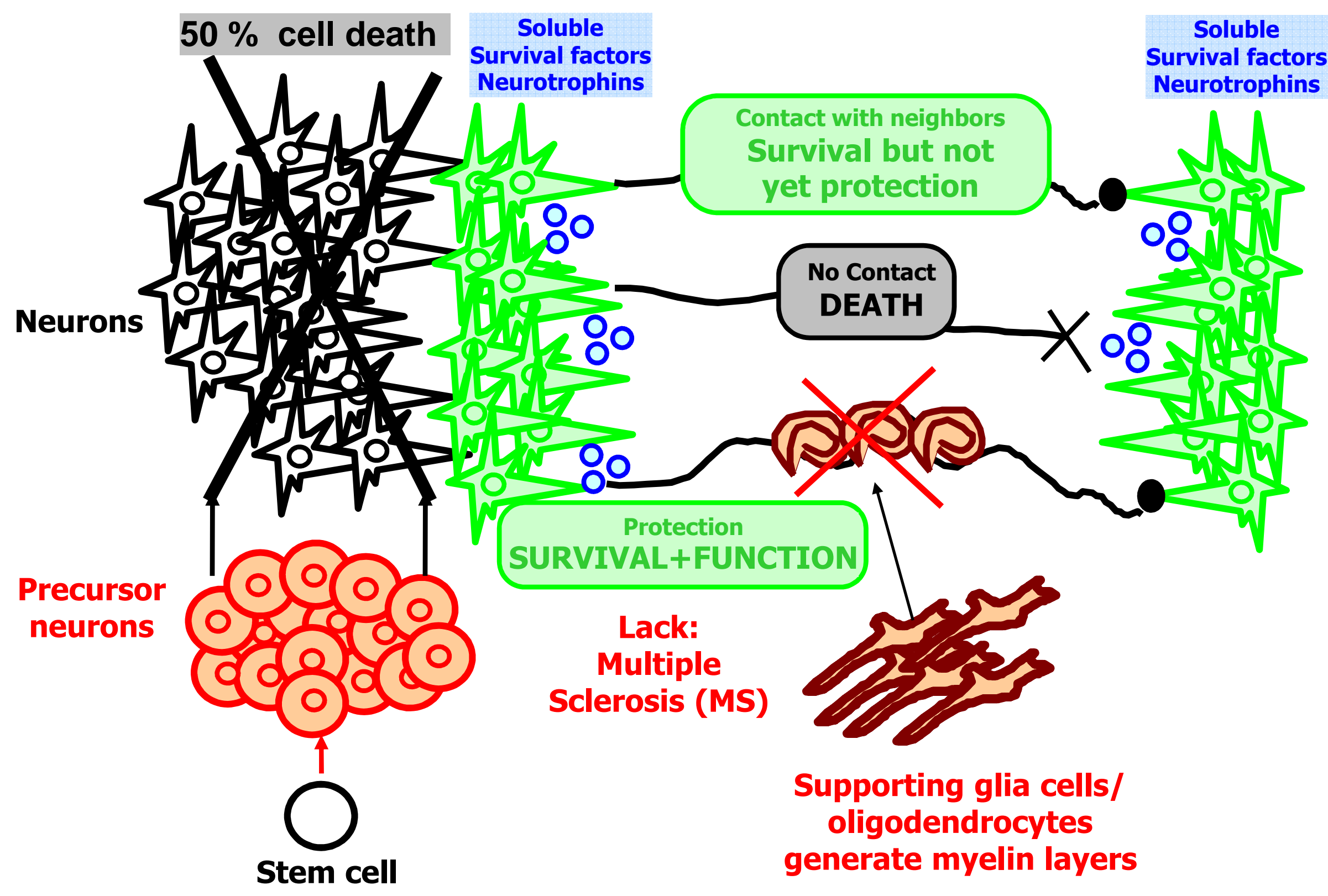




\section{But can also go beserk if uncontrolled}

Too much neuronal cell death leads to neurodegenerative diseases such as Alzheimer, Parkinson, Huntington, ALS, etc.

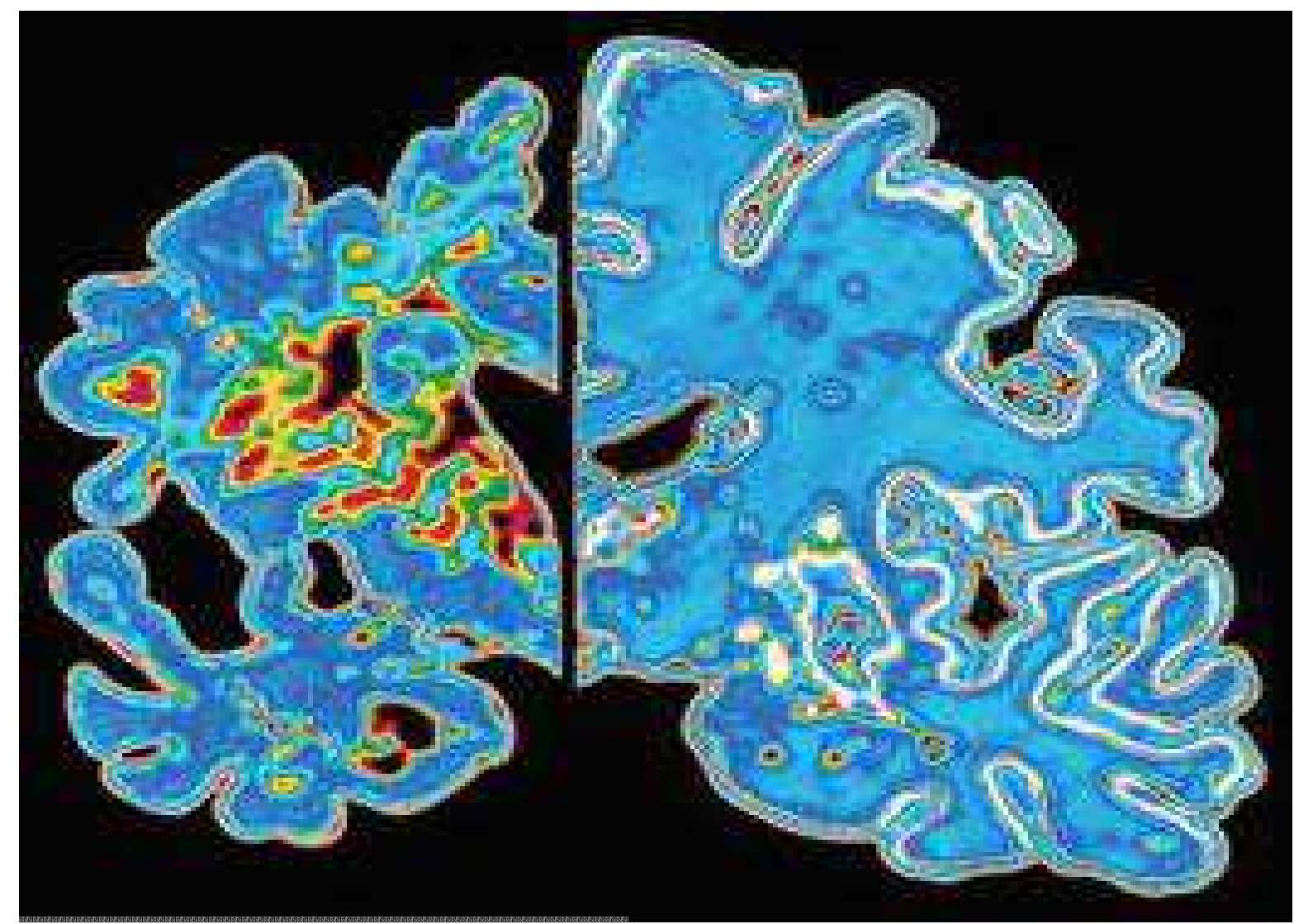

Alzheimer

Patient

Shrunk brain half

Healthy

Individual

due to neuronal cell death 


\section{Where does programmed cell death occur in our adult body on a daily basis?}

In regenerating tissues/cells:

- Blood/hematopoietic system

- Epithelia (skin, digestive tract, lung, liver, kidney)

- Blood vessels (endothelium)

- Peripheral nerves

Not or only in limited amounts

- Central nervous system (brain, spinal cord)

- Muscles (skeletal, heart)

Average cell turnover in humans

$\sim 1 \times 10^{14}$ cells

$\sim 200$ cell types

$\geq 1 \times 10^{6}$ turnover/sec 


\section{Programmed cell death is essential to correctly regenerate blood cells}

\section{Hematopoiesis}

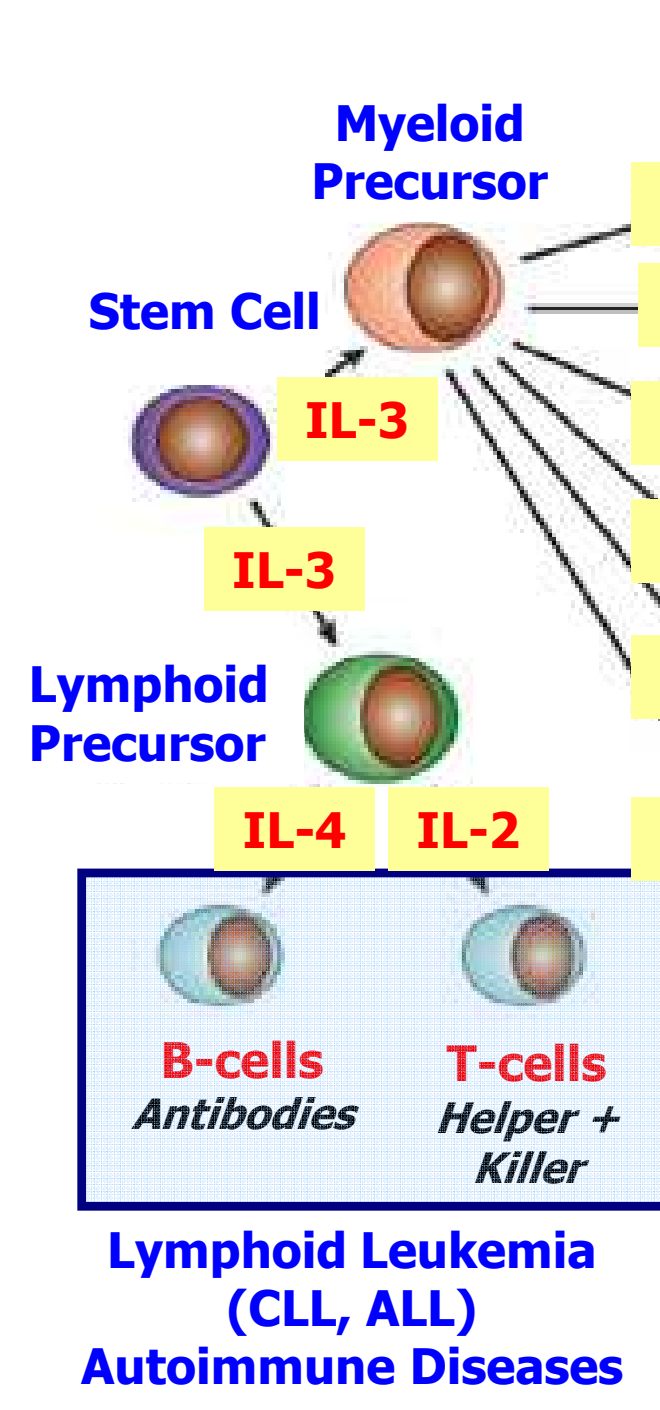

Tages

Ende

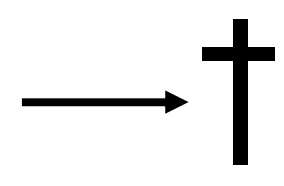

$\longrightarrow$

Oxygen carriers

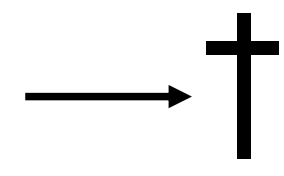

Wound healing

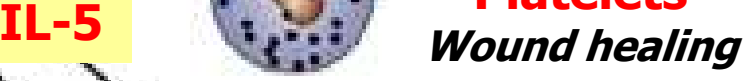

Eosinophils

Neutrophils

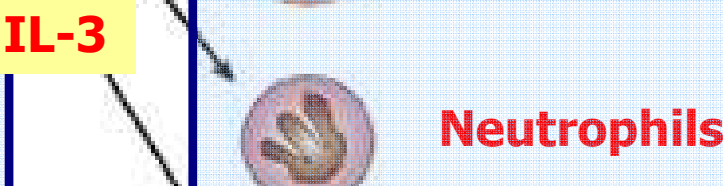

Monocytes

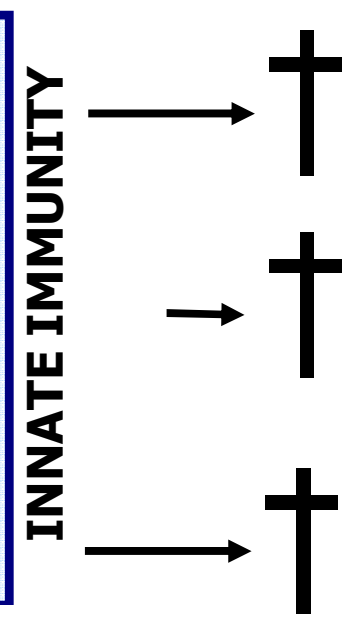

Myeloid Leukemia

(CML) 


\section{Interaction of killer $\mathbf{T}$ cell with infected cell: A fatal "KISS"}

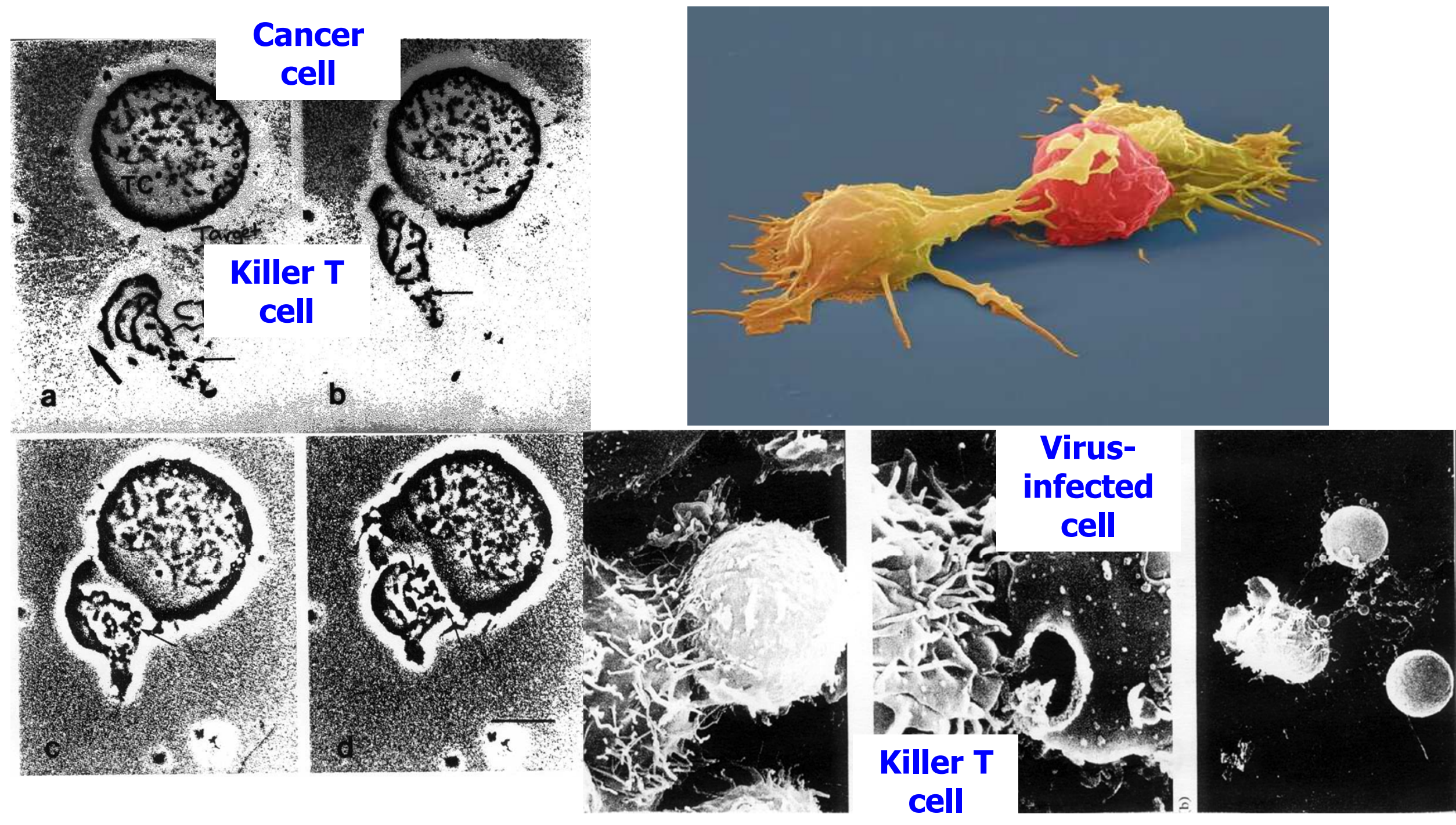

Source: Alberts et al. 2013 


\section{Programmed cell death of epithelia (surface of the skin, intestine, organs, etc.)}

- Outer cell layer of the skin (keratin packed flakes cornea, horny layer)

- Differentiated cells at the tip of intestine villi

- Breast epithelial cells after lactation 


\section{Most damaged, used-up or misplaced cells in our body die by APOPTOSIS}

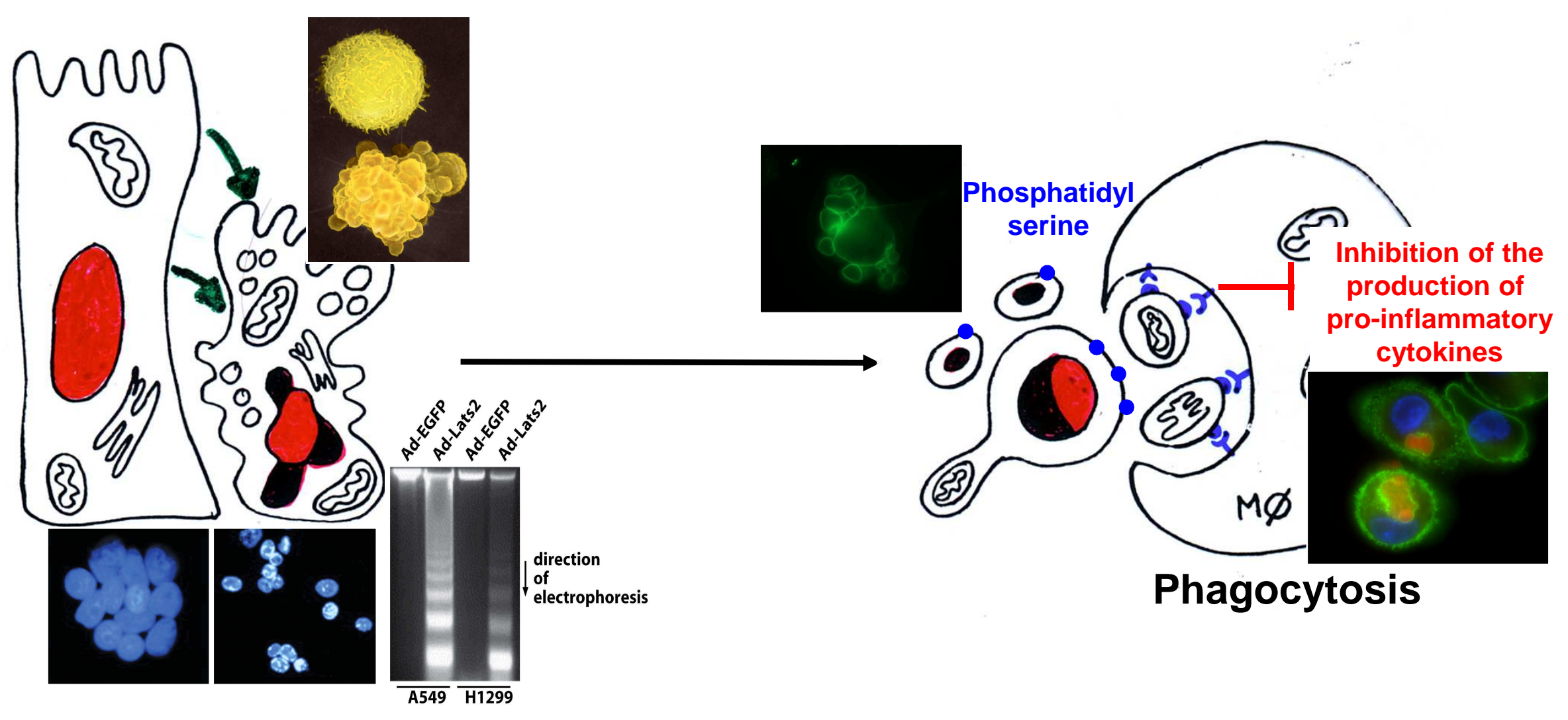


Apoptosis
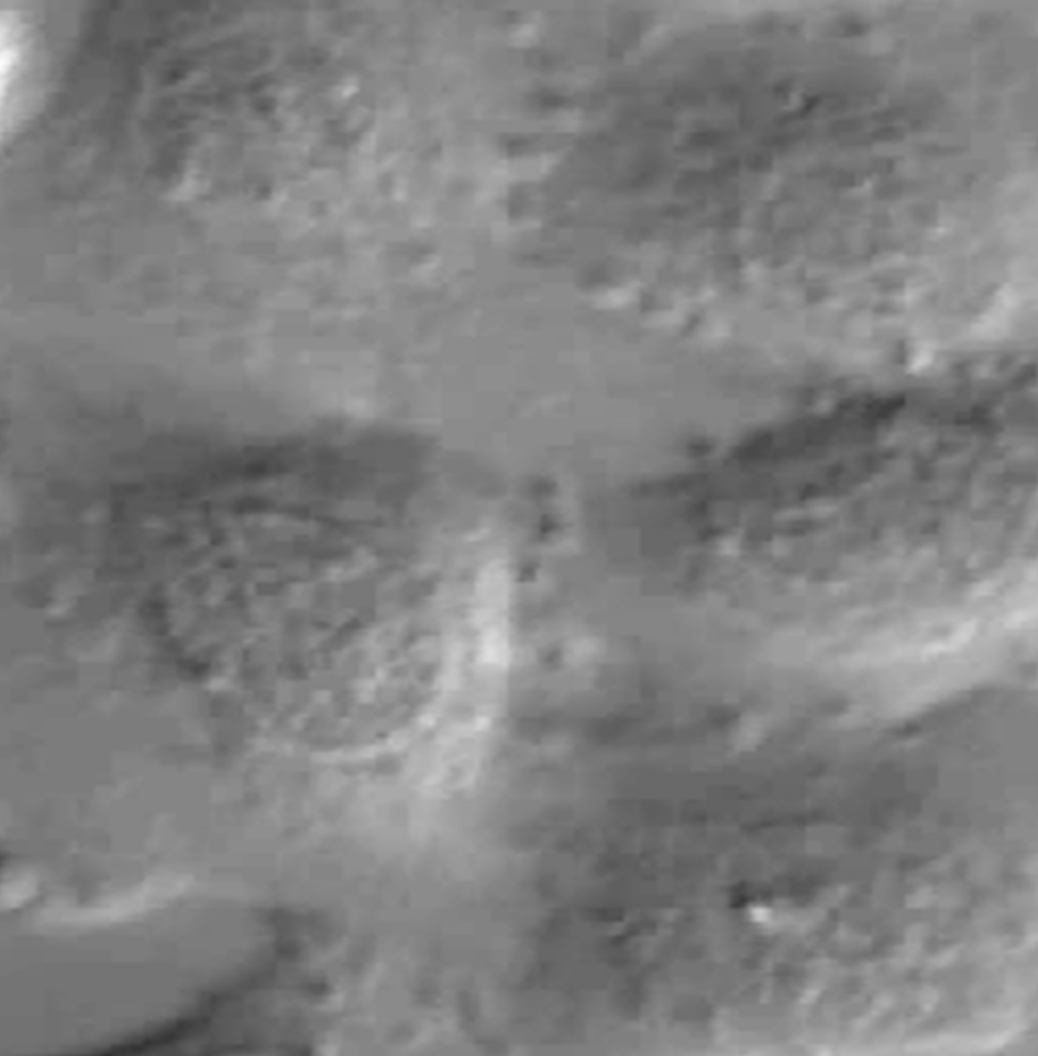
Irradiation, chemotherapeutics, viruses, bacteria, TNF-like cytokines, Lack of survival factors, cell-matrix-(anoikis) and cell-cell interactions 1

\section{BH3-mimetic}

Inactive monomeric

Pro-caspase-9

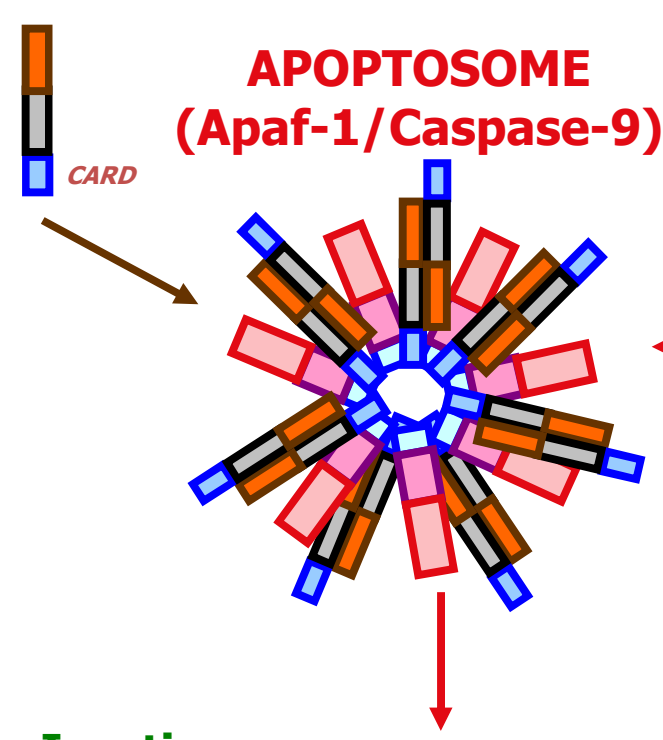

Bcl-2-like INHIBITORS

(Bcl-2, Bcl-xL, Bcl-w, Mcl-1, A1)

BH3-only ACTIVATORS (Bim, Bad, Bid, Bik, Bmf, Puma, Noxa, Hrk, Beclin-1)

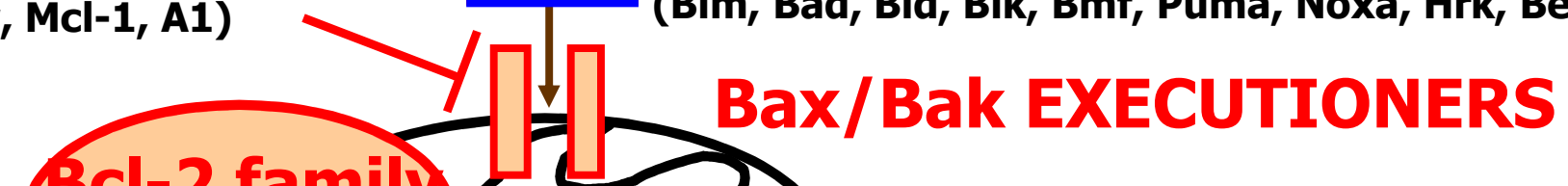

Inactive

Pro-Casp-3/-7
Dimer

Active

Caspase-3/-7
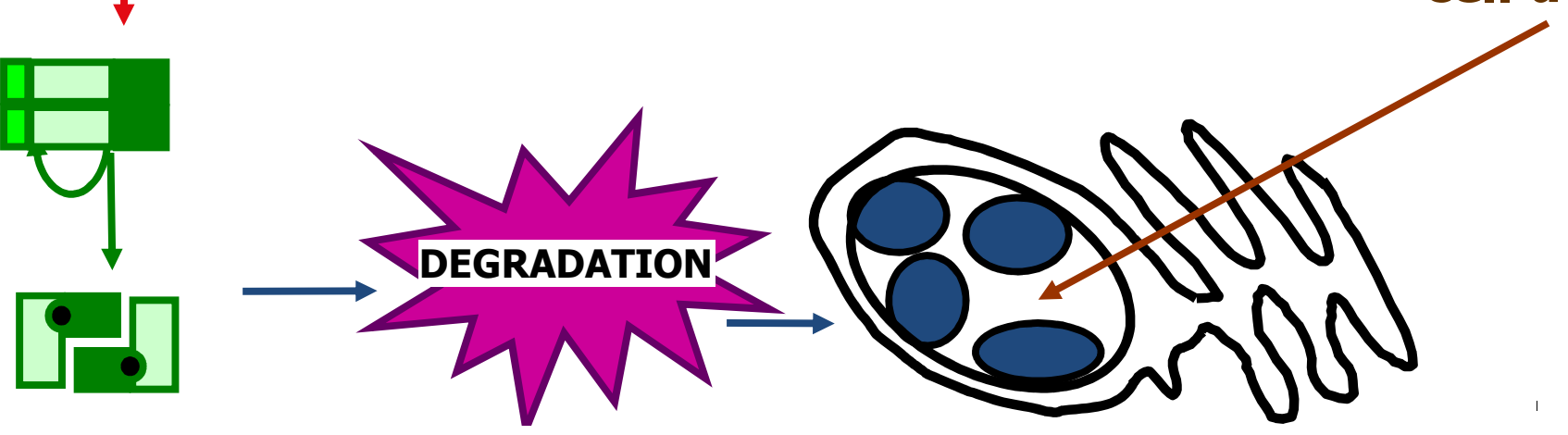

Caspase-independent cell death? 


\section{Is it possible and/or does it make any sense to prolong human life beyond 120 years?}

Short answer is: NO!!! 


\section{Scientific Aspect}




\section{Accumulation of genetic defects/mutations with every cell cycle, even in quiescent cells}

Regeneration Rate

$\sim 1 \times 10^{14}$ Cells

$\sim 200$ Cell types

$\geq 1 \times 10^{6}$ regenerate/sec

\section{Error Rate for Mutations}

$\sim 3 \times 10^{9}$ Basepairs

Precision of repair: $10^{-9}$

Per cell cycle: 3 bp mistakes d.h. per sec $3 \times 10^{6}$ mistakes

But: Most mutated cells die, mutations do not cause negative effects for the cells or fall into irrelevant genomic areas (introns, non-functional regions, wobble of the codon etc.) or aberrant cells are effectively eliminated by the immune system

In the end we may end up with one mutation per sec that is fix But these mutations accumulate over 90-100 years of our life and we can follow them now by rapid, whole genome ("next generation" or "deep" sequencing) 


\section{So when does it get dangerous, detrimental for us to develop diseases such as cancer}

Only a small group of genes are crucial for carcinogenesis:

Oncogenes (gas pedal) and tumor suppressor genes (breaks) Allelic mutations in tumor suppressor genes can be inherited

MUTATIONS IN THOSE GENES PROVIDE TO THE CELLS A SELECTION ADVANTAGE FOR CELL PROLIFERATION AND/OR SURVIVAL

Like DARWIN: Mutation - Selection - Evolution (of Tumors) 


\section{Tumor formation: Several genetic changes Uncontrolled cell division and lack of cell death of damaged, used-up cells}

Accidentially a damaged, used-up cell does not die anymore due to a genetic change (mutation)

A second genetic change (mutation) leads to enhanced cell division of the damage cell but still controlled

3 genetic changes (mutations) trigger uncontrolled cell division, but still benign tumor

4-6 or more genetic changes leads to malignant tumor;

it breaches the barrier, emigrates into the blood and spreads to other tissues (metastasis)

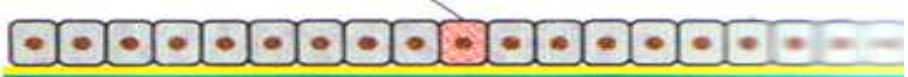

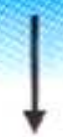

cell with 2 mutations
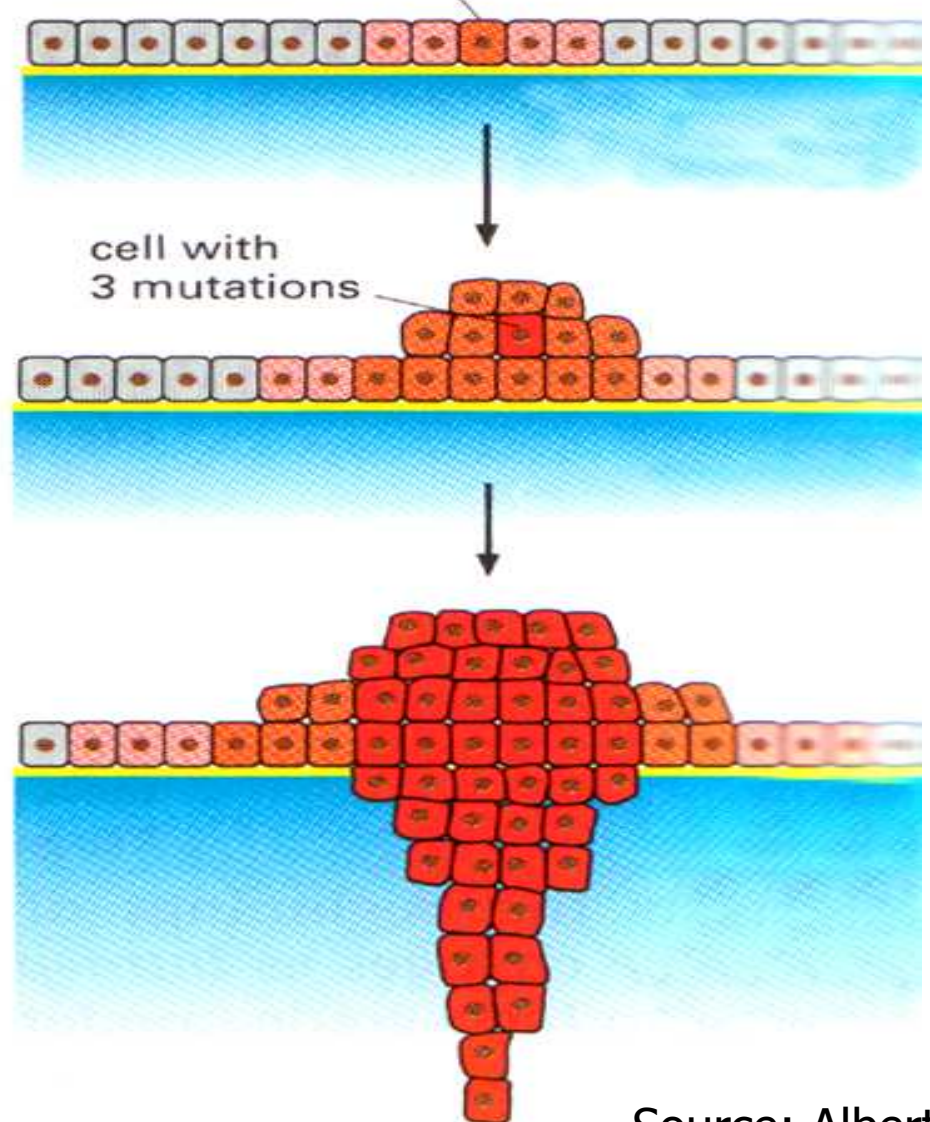

Source: Alberts et al. 2013 


\section{Several Genetic Changes Characterize a Multistep Carcinogensis Process}

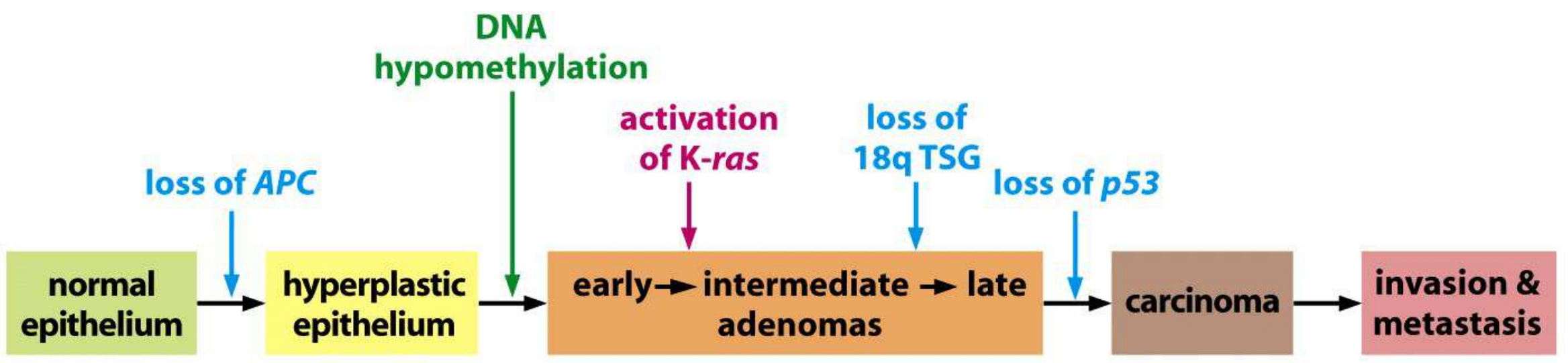

Leukemia: ca. 3 mutagenic events

Carcinoma: ca. 7 mutagenic events

Newest Studies on Breast Cancer Profiliing

(Gene Arrays):

178 Genetic Changes

11 Carcinogenic 


\section{Origin of genetic changes (mutations) which lead to tumor formation \\ i.e. that cells survive and divide in uncontrolled ways}

Chemicals, toxins, asbest, smoking, alcohol

bad nutrition

(high in fat, nitrates, salt, fried, grilled food

low in vegetables and fibres)

Irradiation

(UV, gamma, X-ray, radioactivity)

\section{$80 \%$}

Caused by

life style

i.e. mostly

PREVENTABLE
Tumor Viruses

Papilloma (cervical cancer)

Hepatitis (liver cancer)

Epstein Barr (lymphoma)

\section{$10 \%$}

Regular check-ups

Vaccination

Inheritance

Transmission parent-child

$10 \%$

Prophylaxis

Genetic screening

Check-ups 


\section{Tumorincidence and Mortality}

Absolute number of tumor diseases is increasing!

But....

The age-adjusted/-standardized tumorincidence remains constant !!!

The age-adjusted/-standardized tumor mortality is slowly decreasing !!!

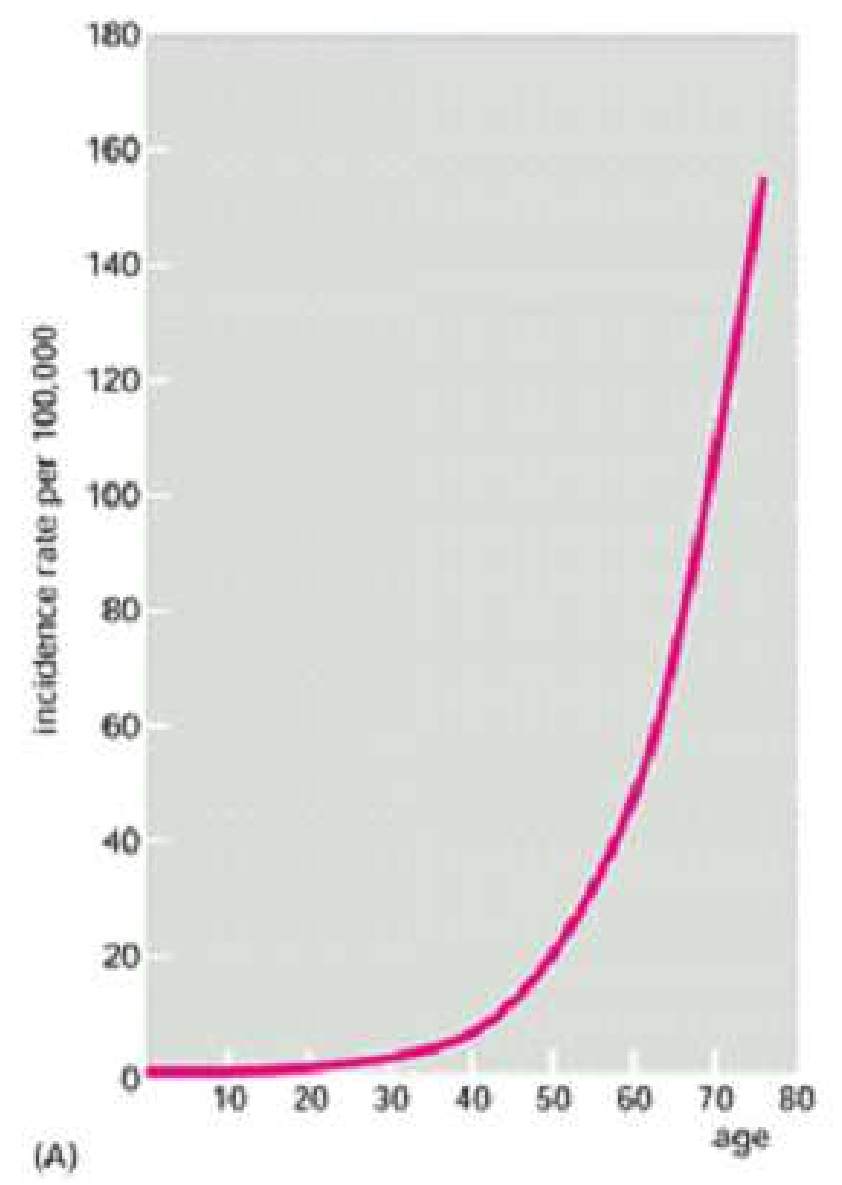




\section{Anti-cancer treatments}

We can and will be able to save more young and older people from cancer with better targeted, precision therapy

\section{But}

Cancer cells will always find ways around, activate other constitutive proliferation and survival pathways and accumulate more mutations which confer treatment resistance

The older we get, the more likely this is We will never outrace cancer completely, never win the war against it entirely if we want to live longer 


\section{How do we treat cancer today?}

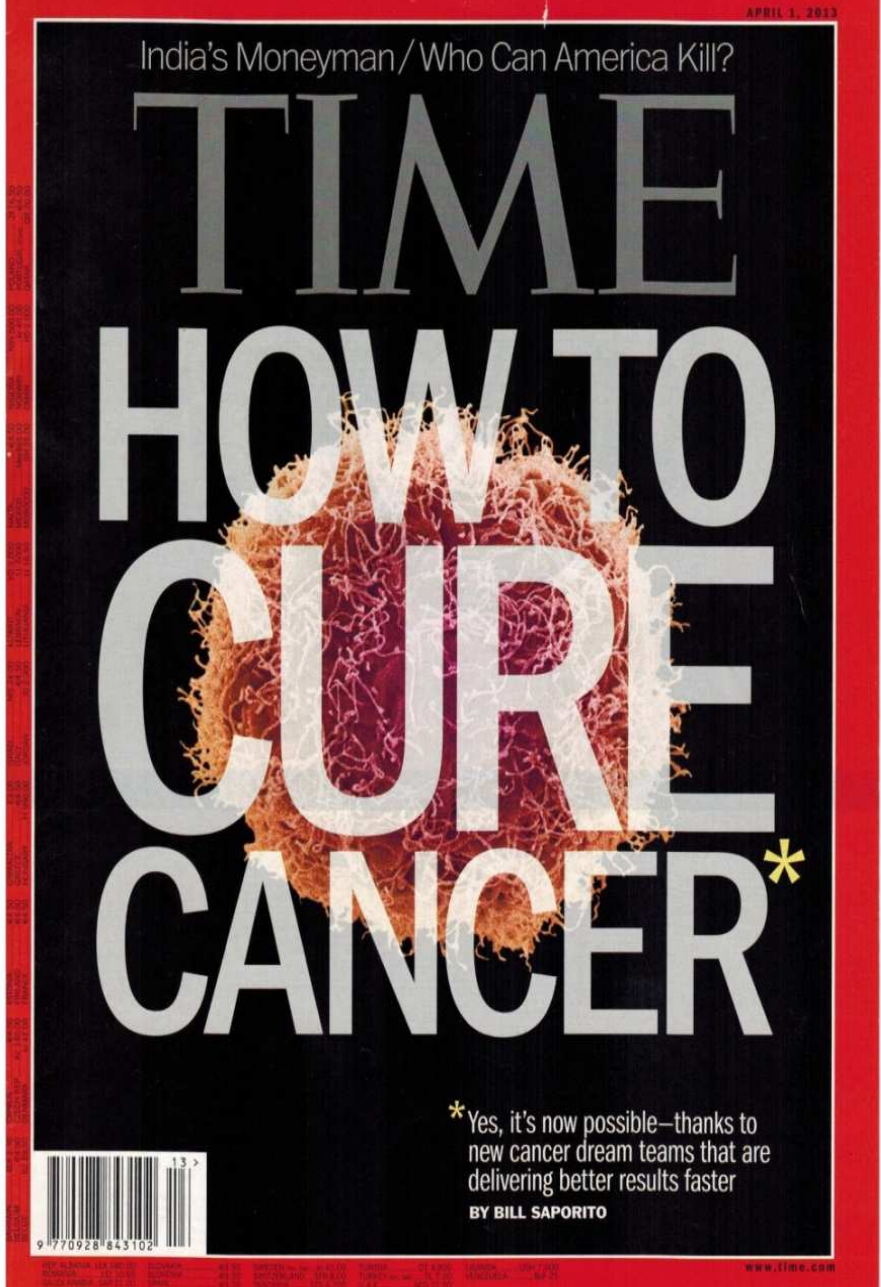

In the past and still ongoing

- $\quad$ Cytotoxic drugs

Now and in the future

- $\quad$ Targeting the "hallmark" pathways by

- monoclonal antibodies

- small molecule (e.g. kinase inhibitors)

- "Liberating" endogenous immunity

- Transgenic T cells

- Gene therapy?

- Supportive drugs and care 


\section{Targets for precision therapy are components of survival and proliferation pathways (Cancer $=$ signaling disease)}

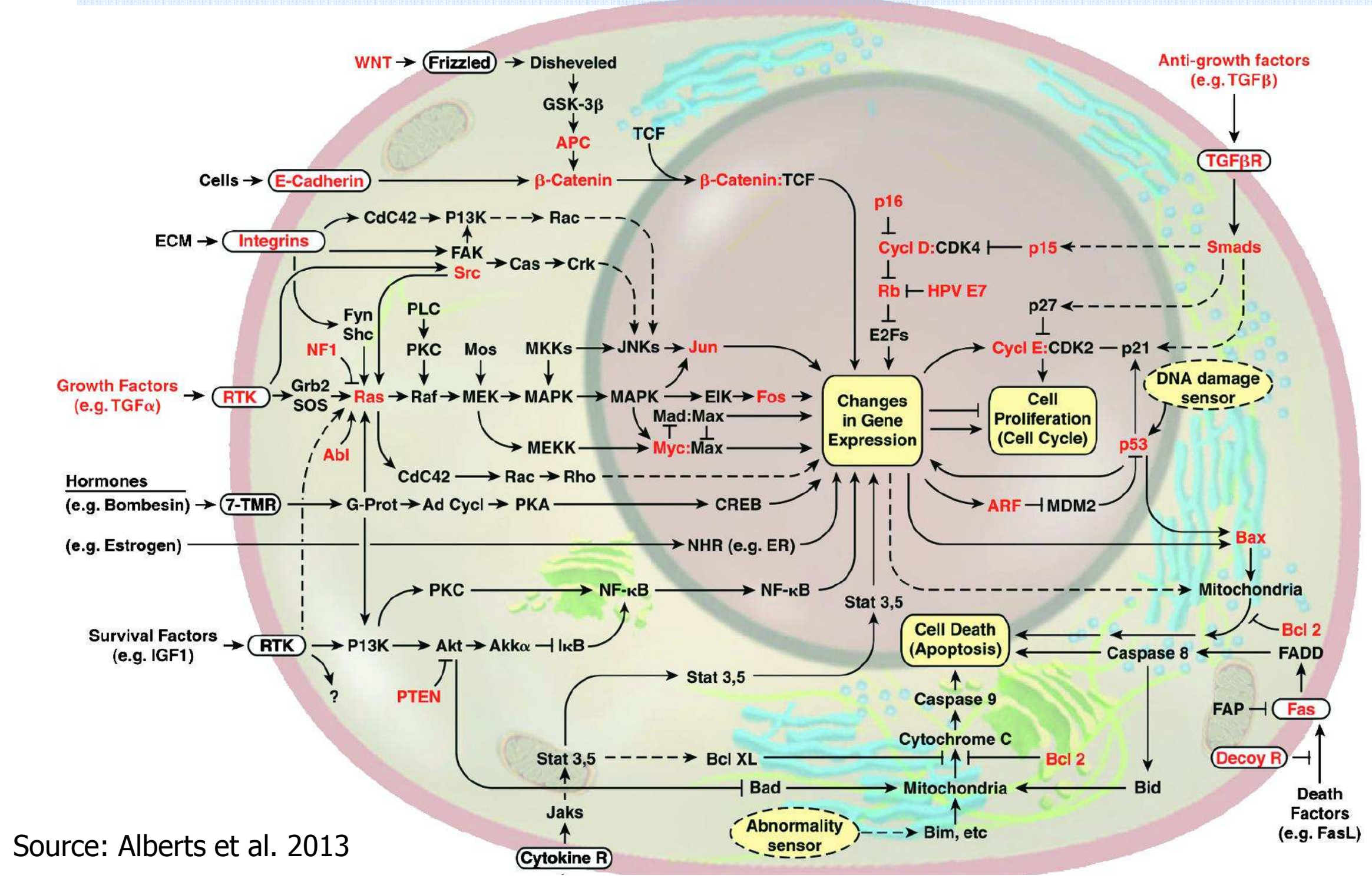




\section{How does precision therapy look like?}

Hit the target which the cancer cells entirely depends on (are "addicted" to) The most robust nodule in the pathway

\section{But}

This is not always the case, as cancers have mutations in several genes which contribute to carcinogenesis requiring combination therapies 


\section{Block overexpressed, constitutively active, dimerized HER2 receptors with antibodies in breast cancer (Herceptin, Trastuzumab)}

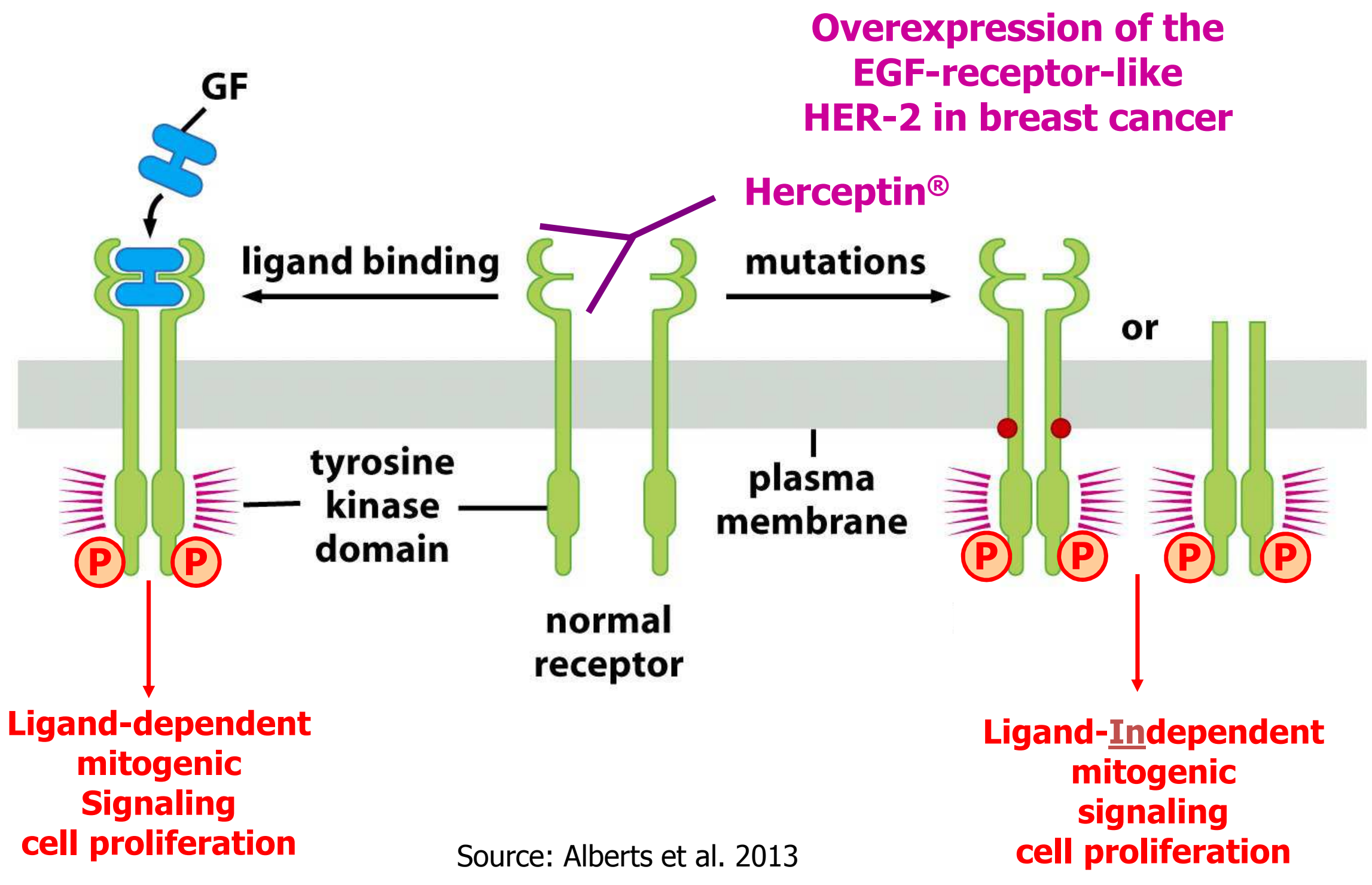




\section{Inhibit constitutively active, mutated EGF receptors with small molecule inhibitor in lung cancer (Iressa, Gefitinib)}

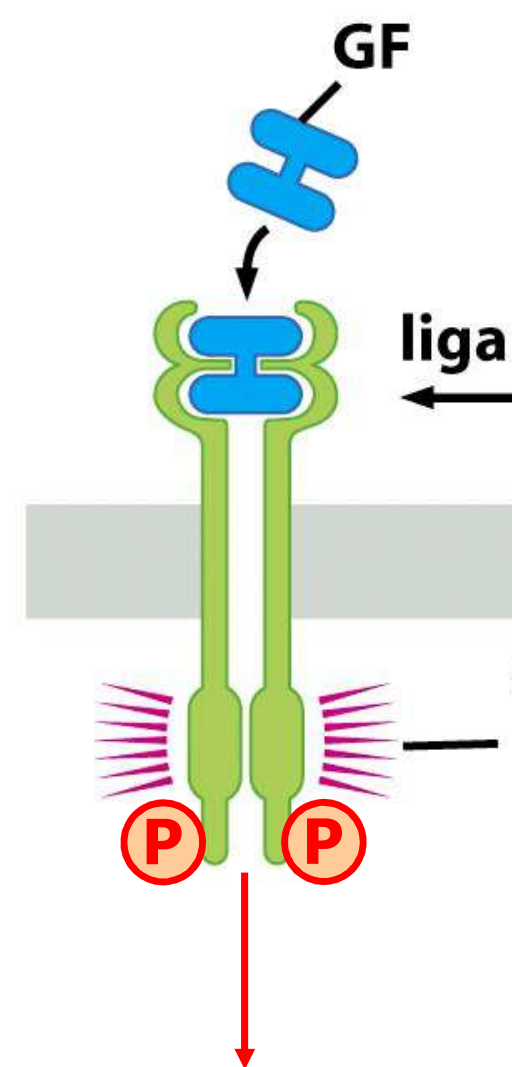

Ligand-dependent mitogenic Signaling cell proliferation
Mutationen in EGF-R of a subclass of lung tumors (non-smokers!) 


\section{Inhibit constitutively active $\mathrm{BCR}-\mathrm{ABL}$ protein kinase with small molecule inhibitor in CML (Gleevec, Imatinib)}

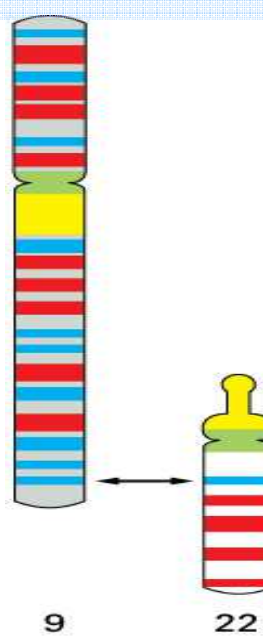

Bcr-Gen auf Chromosom 22

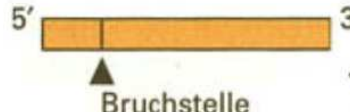

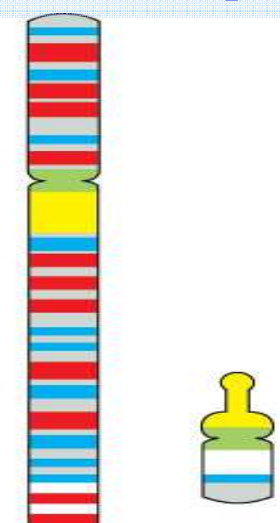

$22 q^{-}$

(Ph ${ }^{1}$ )

Abl-Gen auf Chromosom 9

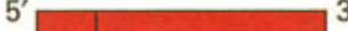

Bruchstelle

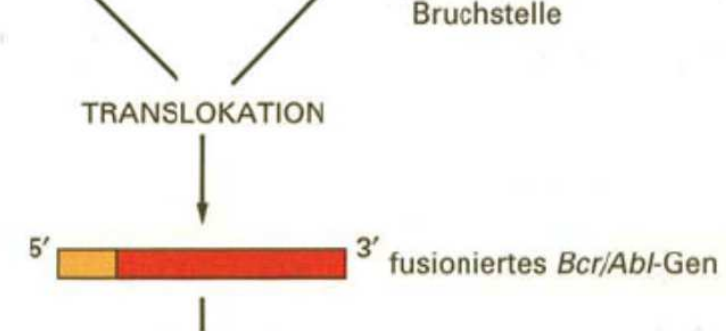

TRANSKRIPTION

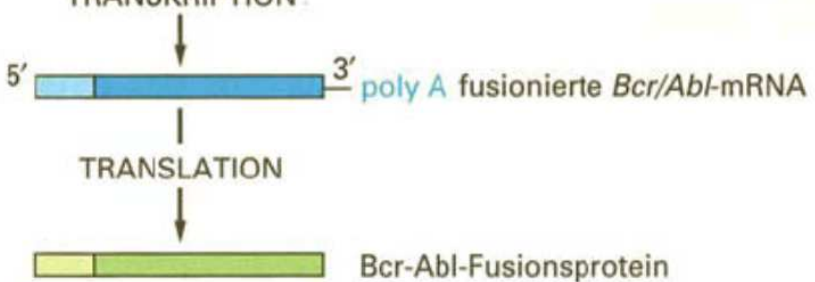

Bcr-Abl-Fusionsprotein

Translocation $\mathbf{t}(9 ; 22)$

(Philadelphia chromosome)

leading to a BCR-ABL fusion and the generation of chronic myeloid leukemia (CML)

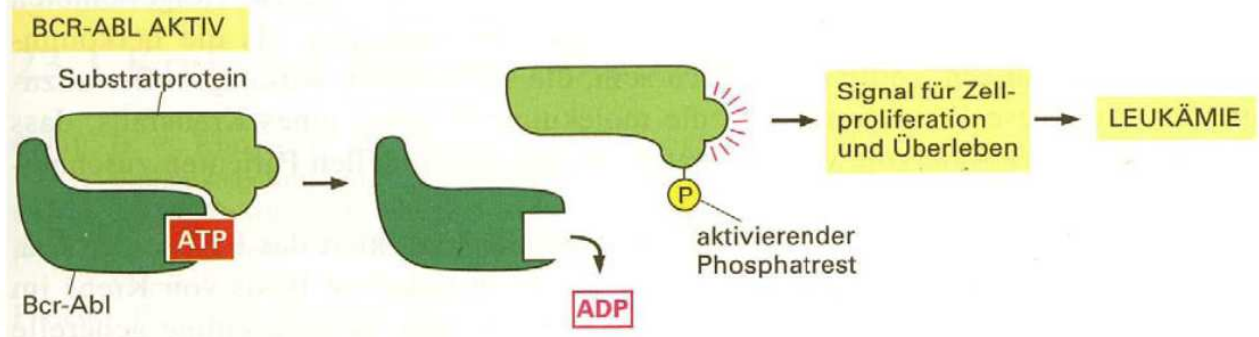

BCR-ABL GEHEMMT DURCH GLEEVEC

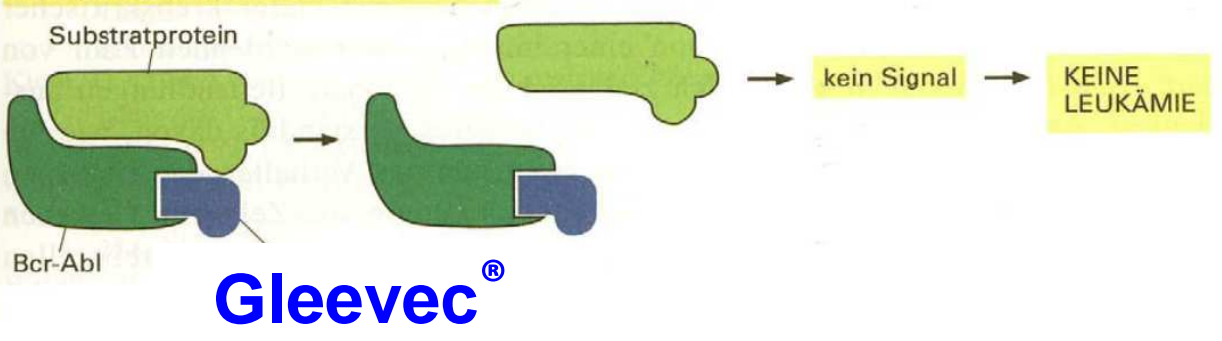




\section{Development of treatment resistance}




\section{Mutated BCR-ABL protein kinase is not inhibited by Gleevec anymore Second generation drug is needed}

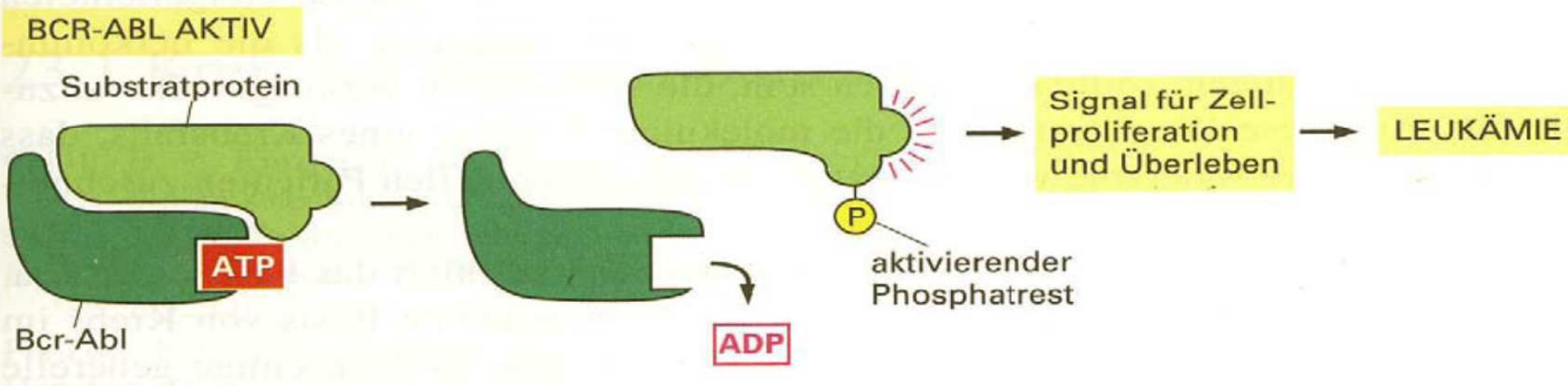

BCR-ABL GEHEMMT DURCH GLEEVEC

Substratprotein

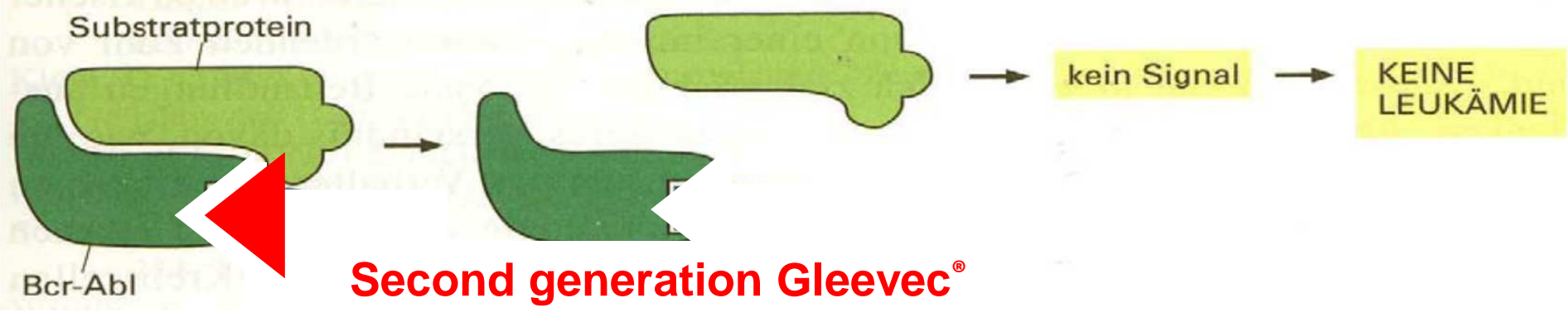

$\square$ Gleevec $^{\circledR}$ 
Survival/mitogenic pathways have negative feedback loops to shut down parallel pathways

\section{If you block the former}

the latter becomes active (Vemurafenib, B-Raf inhibitor) 


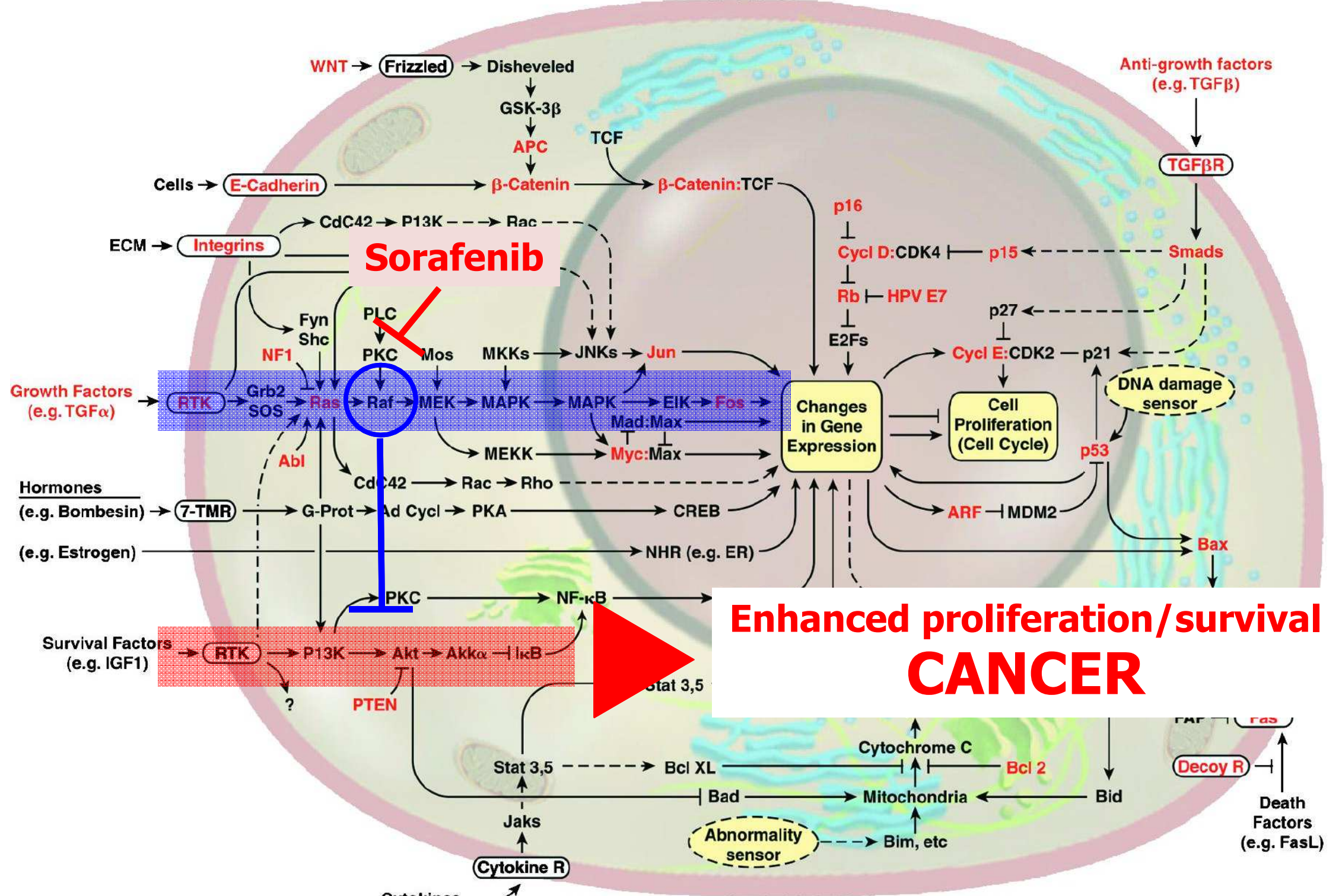




\section{Cancer immunotherapy using anti-PD-L1}

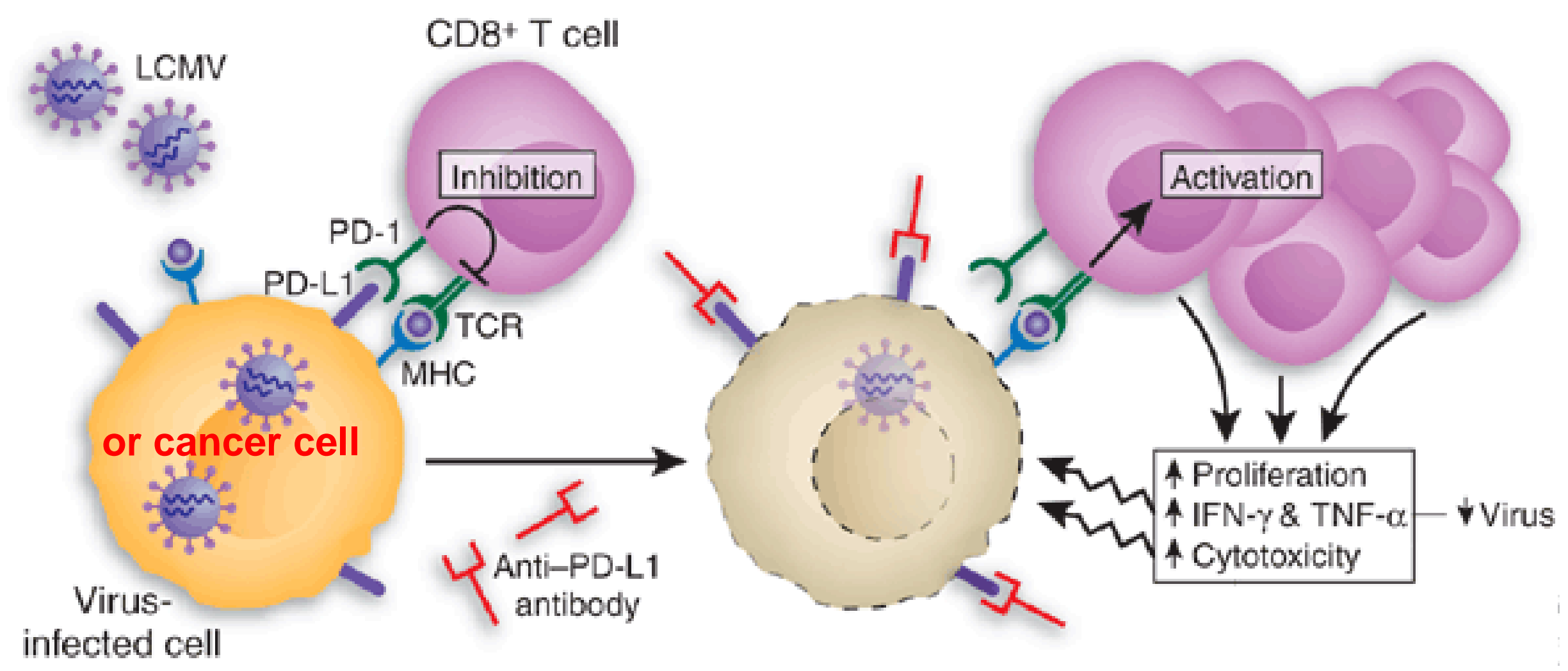

Nature Medicine 12, 276 - 277 (2006) 
We are prone to die because we are not perfect and nature is so complex that it will always find a way around our treatment impact

Nature is so fascinating that humans will never understand it completely

Christoph Borner, PhD thesis 1988

Almost a bit theological, spiritual 


\section{Social Aspects}

- Overpopulated earth

- Not enough resources to feed all people

- Not enough resources to provide jobs for all people

- Problem of financing the elderly

- Increased health costs 


\section{Ethical Aspects}

Whole genomes sequencing to find errors - the bad genes

- Surge of information that we cannot (yet) understand

- Problems of counseling, do we tell everything?

- Who has the right to know what?

- How are the data stored and distributed?

- How can we prevent that data get into wrong hands?

- What about defects for which we do not have any medicine? 


\section{Ethical Aspects}

Improve repair system so that less mutations accumulate

- How are we going to do that? Overexpress a specific repair gene?

- Giving a pill that improves repair?

- Even if it worked, how can we prevent mutations in repair genes? 


\section{Ethical Aspects}

\section{Insert good genes by viral-mediated gene therapy or replace bad genes by good genes by homologous recombination (CRISPR/Cas)}

Viruses insert into genome randomly

Danger to activate an oncogene

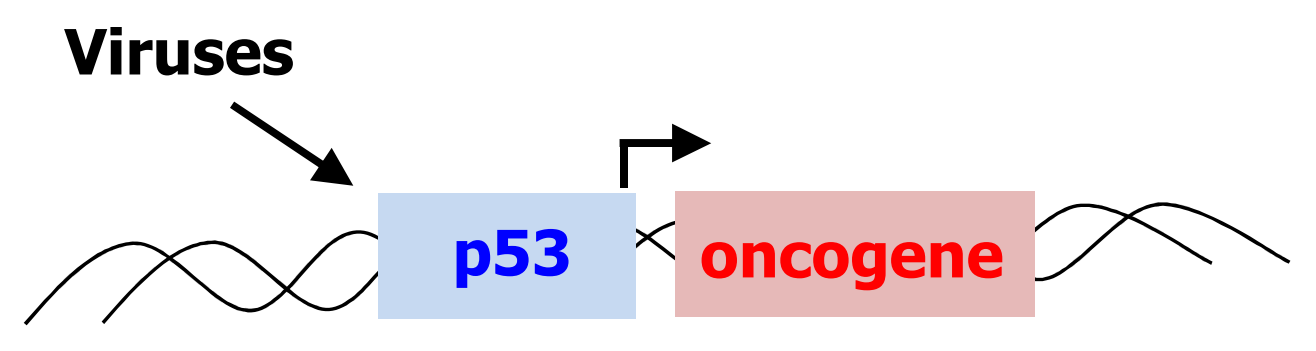

Homologous recombination via CRISPR/Cas9 faithfully replaces defective gene

Problems: Off-target effects, Transfer to next generation Playing God

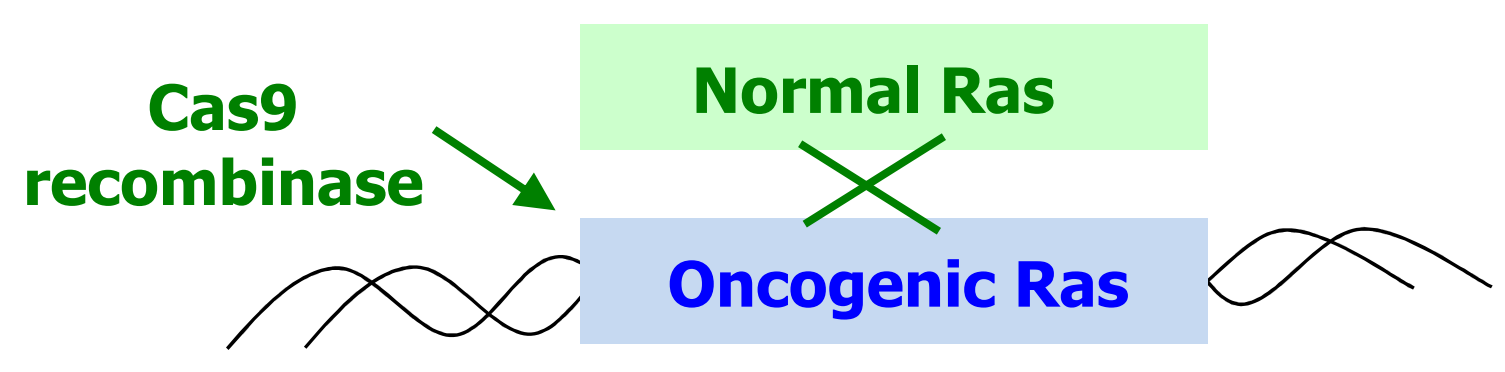




\section{Ethical Aspects}

\section{Prolong life by caloric restriction or use a pill which activates longevity signaling pathways}

Caloric restriction in worms, flies and mice prolongs their lives

Could humans live to $\mathbf{5 0 0}$ years old? Scientists believe genetic tweaks could significantly extend our lifespan

(Mail Online Dec. 2013)

Single mutations in the TOR pathway were known to extend the lifespan of $\mathrm{C}$. elegans by 30 per cent, while insulin-signalling mutations could double the amount of time they lived.

Adding the two together might have been expected to extend longevity by 130 per cent, but the combined impact turned out to be much greater.

(Pankaj Kapahi, Buck Institue of Age Research, Novato, California)

Problems: Humans would starve with the caloric restriction necessary Side-effects of blocking the insulin/mTOR pathways 


\section{5: 10 Rules to prevent Cancer}

1. Do not smoke.

2. Do not smoke.

3. Do not smoke.

4. Avoid carcinogens: asbestos, UV-light, aflatoxine.

5. Diet: moderate in calories, salt, fat, little alcohol.

6. $3 \times$ daily fresh fruit and vegetable

7. Exercise and watch your weight.

8. Vaccination (Hepatitis B, HPV) and treatment of (H. pylori) chronic infections.

9. Good genes.

10. Good luck!! 